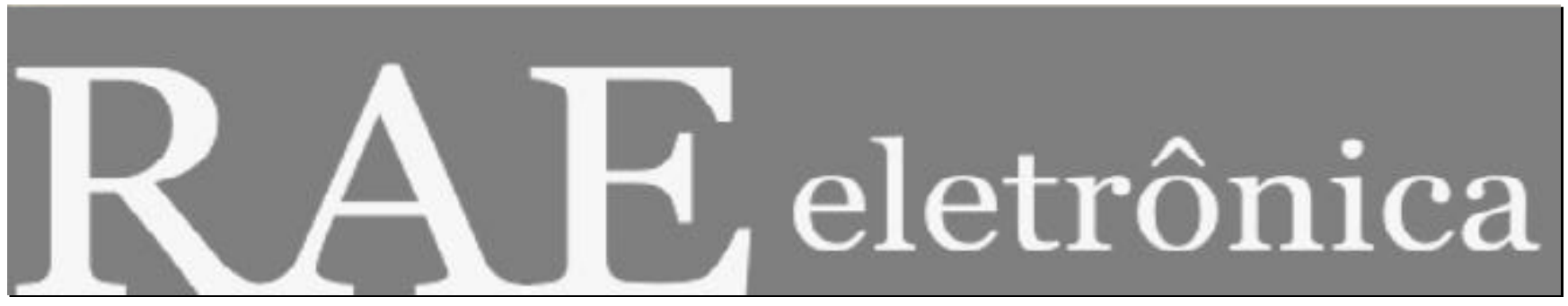

\title{
VALOR EM SERVIÇOS EDUCACIONAIS
}

Por:

\section{Tânia M. Veludo-de-Oliveira, USP} Ana Akemi Ikeda, USP

RAE-eletrônica, v. 5, n. 2, Art. 12, jul./dez. 2006

http://www.rae.com.br/eletronica/index.cfm?FuseAction=Artigo\&ID=3403\&Secao=ARTIGOS\&Volu $\mathrm{me}=5 \&$ Numero $=2 \& \mathrm{Ano}=2006$

CCopyright, 2006, RAE-eletrônica. Todos os direitos, inclusive de tradução, são reservados. É permitido citar parte de artigos sem autorização prévia desde que seja identificada a fonte. A reprodução total de artigos é proibida. Os artigos só devem ser usados para uso pessoal e nãocomercial. Em caso de dúvidas, consulte a redação: raeredacao@fgvsp.br.

A RAE-eletrônica é a revista on-line da FGV-EAESP, totalmente aberta e criada com o objetivo de agilizar a veiculação de trabalhos inéditos. Lançada em janeiro de 2002, com perfil acadêmico, é dedicada a professores, pesquisadores e estudantes. Para mais informações consulte o site www.rae.com.br/eletronica.

RAE-eletrônica ISSN 1676-5648

(C2006 Fundação Getulio Vargas - Escola de Administração de Empresas de São Paulo.

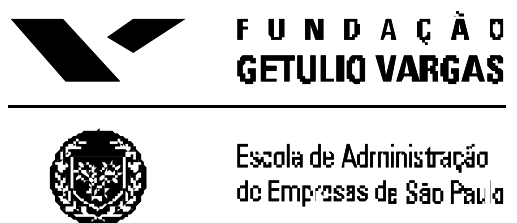




\section{RESUMO}

O objetivo deste artigo é estudar a criação e a entrega de valor em serviços educacionais na perspectiva do estudante. Para isso, foi realizada uma revisão de literatura sobre o conceito de valor e uma análise dos resultados da pesquisa de campo. Foram feitas entrevistas em profundidade com alunos e ex-alunos de cursos de pós-graduação ligados ao curso de marketing. A técnica laddering, também conhecida por escalonamento ou escalada, foi empregada na entrevista e na análise e interpretação dos dados. Os resultados mostram que o valor para o aluno inclui cinco representações-chave: (i) o significado de compartilhar; (ii) a essência do aprender; (iii) o sentido de pertencer; (iv) a expressão do status e da autoconfiança; e (v) as visões sobre contribuições e deveres. Ao final, são feitas sugestões de como a escola pode oferecer valor em seus serviços.

\section{PALAVRAS-CHAVE}

Marketing de serviços, marketing educacional, valor, laddering, ensino superior.

\section{ABSTRACT}

The objective of this article is to study the value creation in educational services, focusing on the student perspective. The literature review is mainly based on the concepts of customer value and means-end chain. In depth interviews with MBA, master and PhD students were made in order to identify the means-end chain elements. The laddering technique was used in both interviews and analysis of results. The student value is represented by five dimensions: ( $i$ ) the meaning of sharing; (ii) the essence of learning; (iii) the sense of belonging; (iv) the status and self-confidence expression; and (v) insights about contributions and duties. Finally, some suggestions on how an education institution can offer value to students are addressed.

\section{KEYWORDS}

Services marketing, educational marketing, value, laddering, high education. 


\section{INTRODUÇÃO}

$\mathrm{Na}$ educação brasileira há uma preemência por mecanismos que gerem valor aos públicos envolvidos com o ensino, como os alunos, professores, organizações e, em última instância, a sociedade. Assim, algumas questões podem ser formuladas: estarão as instituições de ensino criando valor e cumprindo sua missão de formar pessoas com elevado senso de cidadania e com capacidade de atuar profissionalmente de maneira satisfatória? Estarão atendendo às necessidades e aos interesses de alunos, professores, organizações e sociedade? Ou, ainda, estarão preocupadas em conhecer quais são essas necessidades e interesses? Estarão, enfim, conscientes do que representa o valor para seus públicos no serviço educacional?

Apesar de incipiente, o estudo da educação sob o contexto gerencial parece estar ganhando força no Brasil, seguindo a tendência internacional que destaca o surgimento de algumas revistas acadêmicas especializadas nas últimas décadas (Lehmann, 2005). Além de teses e dissertações que começam a tratar do assunto, em 2001 a Associação Nacional dos Programas de Pós-Graduação em Administração (ANPAD) passou a incluir uma área temática dedicada ao Ensino de Administração em seu encontro anual, a EnANPAD. Outra iniciativa é a da RAE-revista de administração de empresas que, em sua edição de abril-junho de 2003, publicou um fórum sobre educação em escolas de negócios.

O objetivo deste estudo é analisar a criação e entrega de valor em serviços educacionais, por meio da abordagem das cadeias meios-fim, centrando-se na perspectiva do aluno. Desse modo, buscouse na literatura o conceito de valor para o cliente e, em seguida, foi realizada uma pesquisa de campo com estudantes. Para se evitar interpretações equivocadas no estudo integrado de marketing e ensino, é importante esclarecer que o termo cliente é utilizado como referência à unidade receptora que compõe uma relação de troca, que neste caso é o aluno.

\section{CONCEITO DE VALOR PARA O CLIENTE}

Alguns dos termos mais comumente empregados para explicar o conceito de valor para o cliente são qualidade, valia, benefícios e utilidade. Contudo, quando analisados de forma individual, verifica-se que o sentido atribuído particularmente a cada um deles assinala significados bastante peculiares e 
distantes um dos outros. Tal falta de consenso é discutida nos trabalhos de LeBlanc e Nguyen (1999) e Veludo-de-Oliveira e Ikeda (2005), nos quais os autores realizam ponderações sobre diversas definições de valor como as sugeridas por Holbrook (1986, 1994), Zeithaml (1988), Sheth, Newman e Gross (1991). Por se alicerçar em uma profícua discussão que comparou pontos comuns e divergentes de uma série de propostas, este artigo adota a conceituação de Woodruff (1997, p. 142), que afirma que "valor para o cliente é a preferência e avaliação de um cliente relativas a atributos de produto, desempenho desses atributos e consequiências advindas do uso que facilitam (ou dificultam), para esse cliente, a tarefa de atingir seus objetivos e propósitos em situações de uso".

Essa conceituação incorpora a noção de valores desejados e recebidos e assevera que o valor para o cliente se origina das percepções aprendidas, de preferências e avaliações. A definição também salienta o valor diante de situações de uso do produto, vinculando atributos de produtos e seu desempenho às conseqüências e aos objetivos pretendidos com seu uso.

A idéia de relacionar atributos, conseqüências e valores pessoais (objetivos ou estados finais desejados) é ancorada na estrutura conceitual do modelo de cadeias meios-fim. Tal modelo foi idealizado por Gutman (1982) para fornecer uma estrutura teórica capaz de interligar os valores dos consumidores a seus comportamentos.

Gutman (1982, p. 60), partindo de estudos anteriores (como os de Young e Feigin, 1975; Howard, 1977; Vinson, Scott e Lamont, 1977), frisou que "meios são objetos (produtos) ou atividades nas quais as pessoas se engajam (correr, ler). Fins são estados de existência valorados, como felicidade, segurança e realização. A cadeia meios-fim é um modelo que busca explicar como uma seleção de um produto facilita o alcance de estados finais desejados".

Essa abordagem distingue três níveis de associações, que partem de atributos de produtos (A) para conseqüências $(\mathrm{C})$ e de conseqüências para valores pessoais $(\mathrm{V})$. Uma seqüência A-C-V forma o que Gutman (1982) denominou cadeia meios-fim, ou ladder, como explicam Botschen, Thelen e Pieters (1999, p. 39-40):

A cadeia se inicia com os componentes de produto, serviço ou comportamento (atributos) e estabelece uma seqüência de ligações com autoconceitos (valores pessoais) por meio de consequiências ou benefícios produzidos por certos atributos do produto, serviço ou comportamento. Isso forma uma cadeia meios-fim, na qual atributos são os meios pelos quais o produto, serviço ou comportamento fornece conseqüências desejadas ou valores [...]. 
O conjunto formado por várias cadeias meios-fim é representado no mapa hierárquico de valor (HVM), que indica a relação entre todos os atributos, consequiências e valores pessoais relativos ao produto.

O modelo de cadeias meios-fim enfatiza por que e como os atributos dos produtos são importantes, indo alé $\mathrm{m}$ do entendimento de suas propriedades funcionais, ou seja, partindo para a compreensão de seus significados na vida do indivíduo. São quatro os pressupostos que o sustentam. O primeiro é que os valores pessoais, definidos como estados finais desejados da existência, têm um papel dominante no direcionamento das escolhas. O segundo é que as pessoas agrupam em conjuntos ou classes a diversidade de produtos que se apresentam como potenciais meios de satisfação de necessidades e valores. O terceiro é que todas as ações produzem consequiências e o quarto, que os indivíduos aprendem a associar uma conseqüência particular com ações particulares (Gutman, 1982).

Botschen, Thelen e Pieters (1999) lembram que os atributos não explicam as razões que levam um cliente a comprar ou usar um bem ou um serviço, ou se engajar em alguma atividade. Assim, do ponto de vista do consumidor, não são os atributos do produto que de fato contam, mas a solução do problema que se manifesta por meio das conseqüências ou dos valores pessoais subseqüentes.

Corroborando essa idéia, Gutman (1982) - em concordância com Rokeach (1973) - atesta que as conseqüências possuem valências positivas e negativas, dependendo do relacionamento estabelecido com os valores pessoais. O desejo pelas conseqüências positivas e a aceitação das conseqüências negativas são determinados pelo valor pessoal com o qual estão associados. Um aluno pode entender o esforço despendido em horas de estudo como uma conseqüência negativa associada à rigorosa exigência do curso (atributo do produto). Porém, ele insiste em continuar o curso e superar essa conseqüência negativa por acreditar que seus objetivos (valores pessoais) serão alcançados por meio desse esforço. Ele pode acreditar que tal esforço (conseqüência negativa) será revertido em reconhecimento profissional, o que o fará sentir-se realizado (valor pessoal). Cada indivíduo, portanto, forma uma percepção da extensão pela qual a consequiência derivada do uso de um produto irá ajudá-lo a obter os estados finais desejados.

Algumas modificações, como a ampliação dos níveis da cadeia, foram sugeridas ao modelo de Gutman (1982) para preservar certas peculiaridades dos elementos. O modelo ampliado, proposto por Olson e Reynolds (1983), recomenda que os atributos sejam subdivididos em atributos concretos e abstratos, as conseqüências em funcionais e psicológicas e os valores pessoais, em instrumentais e terminais, totalizando seis níveis em vez de três (veja a Figura 1). 
Figura 1 - Níveis de abstração da cadeia meios-fim ampliada

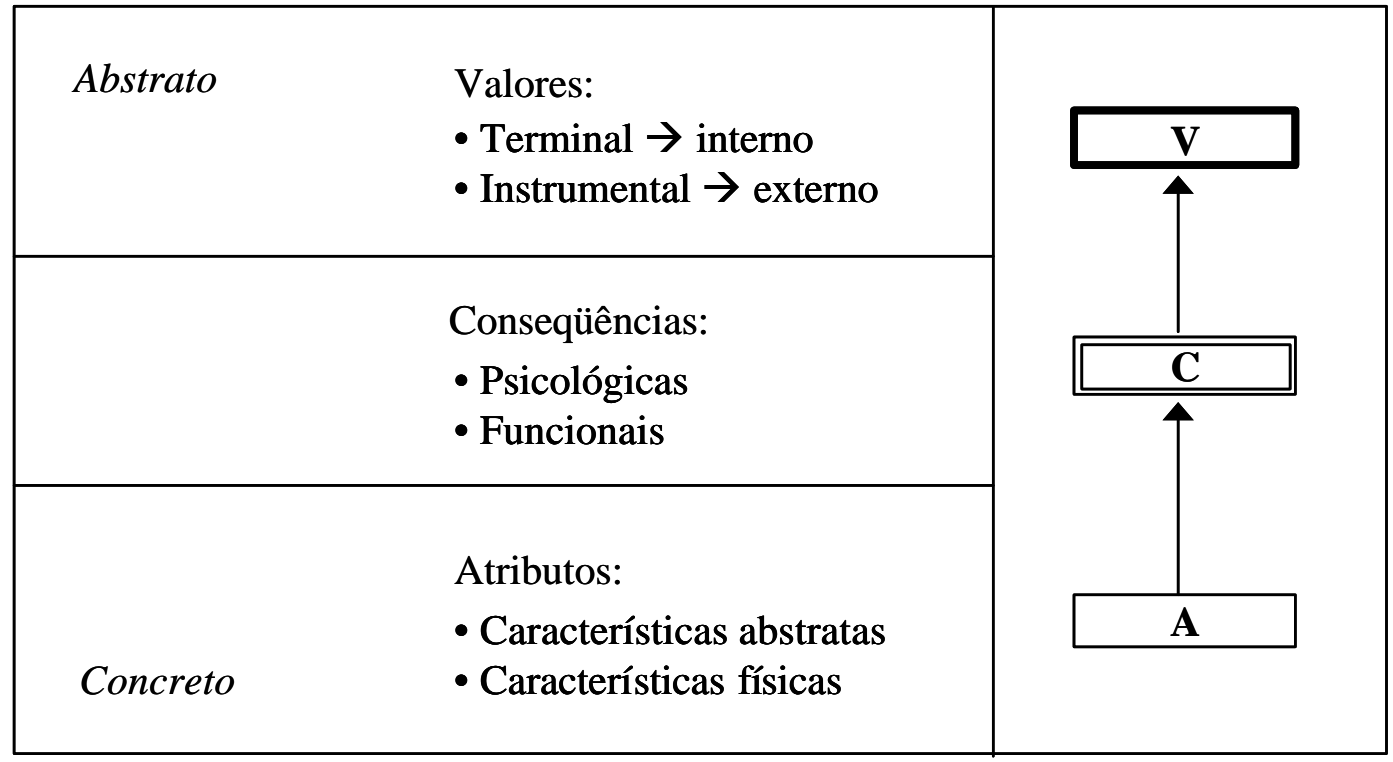

Fonte: Adaptado de Valette-Florence e Rapacchi (1991, p. 31).

\section{Atributos concretos e abstratos}

Os atributos estão no nível mais básico das cadeias meios-fim; "são significados relativamente concretos que representam as características físicas ou observáveis em um produto" (Gengler, Mulvey e Oglethorpe, 1999, p. 176). São definidos pelas características de bens, serviços (Valette-Florence e Rapacchi, 1991) ou comportamentos, que são preferidos e procurados pelos indivíduos (Botschen, Thelen e Pieters, 1999) ou normalmente descritos por eles (Woodruff e Gardial, 1996). Lin (2002) atesta que os atributos podem ser concretos ou abstratos, sendo diferenciados pelo grau de intangibilidade. Exemplo de atributos concretos são preço, cor e peso (Vriens e Hofstede, 2000) e de atributos abstratos são estilo, marca (Lin, 2002) e qualidade percebida (Leão e Mello, 2001).

\section{Conseqüências funcionais e psicológicas}

No nível intermediário da cadeia estão as conseqüências, subdivididas em funcionais ou psicológicas. Elas são "características menos ou não diretamente observáveis" (Vriens e Hofstede, 2000, p. 6), resultado da combinação de vários atributos e se manifestam principalmente com o uso do produto (Valette-Florence e Rapacchi, 1991). "Possuem um significado mais abstrato que reflete os benefícios percebidos (ou os custos) associados a atributos específicos" (Gengler, Mulvey e Oglethorpe, 1999, p. 176) e, por isso, podem suscitar tanto sentimentos positivos como negativos (Lin, 2002). Facilidade de 
uso, conforto e conve niência são exemplos de consequiências funcionais, pois atuam no indivíduo mais diretamente (Vriens e Hofstede, 2000) e têm função utilitária. As consequiências psicológicas são derivadas das funcionais: a imagem sofisticada e o status produzidos pelo uso de um bem servem como ilustração (Valette-Florence e Rapacchi, 1991).

\section{Valores instrumentais e terminais}

Os valores pessoais estão no nível mais abstrato da cadeia e podem ser entendidos como crenças e cognições relativamente estáveis que fornecem uma orientação geral para nossas vidas (ValetteFlorence e Rapacchi, 1991), determinando, regulando e modificando as relações entre indivíduos, organizações, instituições e sociedades (Dibley e Baker, 2001). Segurança e divertimento são alguns exemplos (Vriens e Hofstede, 2000). Os valores pessoais podem ser instrumentais ou terminais (Rokeach, 1973). Os primeiros representam os estados finais da existência, são os grandes objetivos que buscamos, como liberdade e felicidade. Os valores instrumentais são os modos de comportamento que levam aos valores terminais, como a independência e responsabilidade que podem ser necessárias ao alcance da liberdade, por exemplo. Neste trabalho, as cadeias meios-fim serviram como uma nova perspectiva para análise dos serviços educacionais, que é feita a seguir.

\section{METODOLOGIA DA PESQUISA}

$\mathrm{Na}$ análise do valor algumas técnicas se mostram mais adequadas que os métodos tradicionalmente usados para medir satisfação e outros aspectos comportamentais. A laddering, também conhecida por escalonamento ou escalada, por estruturar hierarquicamente as dimensões de valor, é uma das técnicas mais recomendadas e utilizadas para tal finalidade (Reynolds e Gutman, 1988; Reynolds e Whitlark, 1995; Lastovicka, 1995; Gengler e Reynolds, 1995; Grunert e Grunert, 1995; Woodruff e Gardial, 1996; Wansink, 2000; Dibley e Baker, 2001; Lin e Fu, 2001; Foote e Lamb, 2002; Manyiwa e Crawford, 2002; Rugg et al., 2002; Gutman e Miaoulis, 2003; Makatouni, 2002; Urala e Lähteenmäki, 2003).

Desse modo, seguindo as especificações da laddering, foram realizadas entrevistas em profundidade com alunos e ex-alunos de uma instituição de ensino de São Paulo, no primeiro semestre de 2003. A pós-graduação foi o nível de ensino escolhido para análise. No total, foram entrevistados 
nove alunos de MBA, nove alunos de mestrado e nove alunos de doutorado. Durante o curso das entrevistas, foi encontrada repetição nas informações obtidas, o que confirma o alcance de algum grau de saturação e reitera o número de 27 entrevistados como suficiente para compor a amostra. Ainda que os alunos entrevistados pertençam a três segmentos distintos, as análises mostraram que existem semelhanças em suas cadeias de valor. Portanto, neste artigo, primeiramente, enfatizam-se as similaridades entre os grupos, analisando-os como um conjunto de alunos pertencentes à pósgraduação. E, ao final, ressaltam-se as diferenças relacionadas a cada grupo especificamente, realizando-se recomendações voltadas aos alunos de MBA e aos alunos de mestrado e doutorado. O Quadro 1 indica quem são e quantos são os respondentes em cada um dos grupos que participou das entrevistas em profundidade.

Quadro 1 - Públicos abordados nas entrevistas em profundidade

\begin{tabular}{|c|c|c|}
\hline Curso de especialização & \multicolumn{2}{|c|}{ Cursos de pós-graduação acadêmica } \\
\hline MBA & Mestrado & Doutorado \\
\hline $\begin{array}{l}\text { (3) alunos que estavam } \\
\text { iniciando o curso em } \\
\text { fevereiro de } 2003\end{array}$ & $\begin{array}{l}\text { (3) alunos que estavam } \\
\text { cursando os créditos do } \\
\text { programa }\end{array}$ & $\begin{array}{l}\text { (3) alunos que estavam } \\
\text { cursando os créditos do } \\
\text { programa }\end{array}$ \\
\hline Aluno 1, Aluno 2, Aluno 3 & Aluno 10, Aluno 11, Aluno 12 & Aluno 19, Aluno 20, Aluno 21 \\
\hline $\begin{array}{c}\text { (3) alunos que haviam } \\
\text { cursado metade do MBA em } \\
\text { fevereiro de } 2003\end{array}$ & $\begin{array}{l}\text { (3) alunos que haviam } \\
\text { qualificado a dissertação em } \\
\text { fevereiro de } 2003\end{array}$ & $\begin{array}{l}\text { (3) alunos que haviam } \\
\text { qualificado a tese em } \\
\text { fevereiro de } 2003\end{array}$ \\
\hline Aluno 4, Aluno 5, Aluno 6 & Aluno 13, Aluno 14, Aluno 15 & Aluno 22, Aluno 23, Aluno 24 \\
\hline $\begin{array}{l}\text { (3) alunos que já haviam } \\
\text { finalizado o curso em } \\
\text { fevereiro de } 2003\end{array}$ & $\begin{array}{l}\text { (3) alunos que já haviam } \\
\text { defendido a dissertação em } \\
\text { fevereiro de } 2003\end{array}$ & $\begin{array}{c}\text { (3) alunos que já haviam } \\
\text { defendido a tese em fevereiro } \\
\text { de } 2003\end{array}$ \\
\hline Aluno 7, Aluno 8, Aluno 9 & Aluno 16, Aluno 17, Aluno 18 & Aluno 25, Aluno 26, Aluno 27 \\
\hline
\end{tabular}

Fonte: representação proposta pelas pesquisadoras.

As entrevistas tiveram duração média de 50 minutos, foram gravadas e transcritas, sendo submetidas à análise de conteúdo. O LADDERMAP - software comerciável que auxilia o tratamento de dados apoiou as demais fases previstas pela laddering na interpretação dos resultados, a saber: (i) desenvolvimento da matriz de implicação; (ii) construção do HVM; e (iii) determinação das orientações de percepções dominantes (Reynolds e Gutman, 1988). A decisão pelo uso do software baseou-se nos ganhos operacionais proporcionados por ele (Gengler, 1995; Gengler e Reynolds, 1995; Lastovicka, 1995), que, acima de tudo, minimizam o risco de interpretações indevidas. A utilização do LADDERMAP foi possibilitada pelo criador do programa, professor Charles Gengler, que gentilmente o cedeu para a realização da pesquisa. 


\section{ANÁliSE DOS RESULTADOS: O VALOR PARA O ALUNO EM SERVIÇOS EDUCACIONAIS}

A tarefa de se compreender o valor para o aluno estabelece duas etapas preliminares: (i) a identificação dos elementos das cadeias meios-fim, segundo a classificação em atributos, consequiências e valores pessoais; e (ii) a determinação das inter-relações entre os elementos que as compõem, com a apresentação do HVM. Tais etapas subsidiam a interpretação do significado do valor para o aluno.

\section{Os elementos que compõem as cadeias meios-fim}

A identificação dos elementos que compõem as cadeias meios-fim foi realizada mediante análise de conteúdo das entrevistas, indicando os elementos que representam o valor para o aluno em relação aos serviços educacionais.

A categorização das unidades de material escrito das entrevistas gerou 11 atributos concretos, 5 atributos abstratos, 10 conseqüências funcionais, 13 consequiências psicológicas, 6 valores instrumentais e 3 valores terminais, sendo que tais categorias foram fracionadas de acordo com a semelhança dos comentários em termos de significado. A classificação dos elementos segundo tais dimensões seguiu a ordem enfatizada pelos respondentes, obedecendo a seqüência em que os elementos eram lembrados conforme o nível de abstração das respostas. Assim, o corpo docente foi considerado um atributo concreto por ser um componente do serviço educacional, já a reputação foi considerada um atributo abstrato por causa de sua dependência em relação ao corpo docente e a outros atributos concretos. A aquisição de conhecimentos foi classificada como consequiência funcional por ser um benefício proporcio nado diretamente pelo serviço educacional, ao passo que a aceitação social foi classificada como conseqüência psicológica por estar mais relacionada ao sentimento do respondente, sendo esse elemento uma decorrência de uma conseqüência funcional. Por fim, foi atribuída a classificação de valores instrumentais àqueles elementos que atuam como meios para se alcançar os valores terminais, que foram enfatizados como objetivos-fins pelo aluno. O Quadro 2 indica e descreve os elementos que compõem as cadeias meios-fim. 
(01) Corpo discente: perfil de aluno da instituição de ensino quanto a: maturidade, experiência e atividades profissionais, interesses, nível cultural e sucesso na carreira, incluindo os colegas de turma e de curso e ex-alunos em geral.

(02) Corpo docente: perfil de professor da instituição de ensino quanto a: (i) assiduidade; (ii) atenção, disponibilidade e interesse pelos alunos; (iii) atividades e experiências profissionais; (iv) atividades e experiências internacionais; (v) atualização; (vi) conhecimento em sua área de ensino e pesquisa; (vii) dedicação; (viii) didática; (ix) nível cultural; (x) nível de instrução e titulação; e (xi) produção científica.

(03) Custo: sacrifício monetário para a realização do curso, que compreende o preço da mensalidade, o desembolso com gastos indiretos, como xerox e livros, e o custo de oportunidade por estar trocando o tempo de um trabalho remunerado (ou de maior remuneração, no caso de bolsistas) pela dedicação ao curso.

(04) Disciplinas: conteúdo programático, programa de disciplinas do curso e/ou disciplinas que o aluno tem possibilidade de cursar, levando-se em conta a variedade, relevância, atualidade, especificidade e profundidade de temas, de acordo com a área de interesse.

(05) Duração e horários: prazo para conclusão do curso e períodos e dias da semana em que o aluno freqüenta as aulas.

(06) Formato das aulas: técnicas de ensino empregadas no curso, considerando sua adequação aos objetivos da aula, a variedade de métodos utilizados, como a aula expositiva e o ensino em pequenos grupos (seminários, método do caso e jogos de empresas), e a utilização de recursos audiovisuais e tecnológicos.

(07) Infra-estrutura: condições estruturais e sistemas de apoio que garantem o andamento do curso e o processo de ensino e aprendizagem, envolvendo as dependências da instituição, como salas de aula, salas de estudo, biblioteca, laboratório de informática e secretaria, no que diz respeito a equipamentos, iluminação, limpeza, horário de funcionamento, nível de preparação dos funcionários, qualidade, quantidade e variedade do acervo e de materiais disponibilizados no curso, como apostilas, textos extras e indicações de leitura.

(08) Localização: local de estabelecimento da instituição, envolvendo a cidade onde está situada e a facilidade de acesso, incluindo o estacionamento.

(09) Processo seletivo: conjunto de etapas classificatórias e eliminatórias para seleção dos postulantes a uma vaga do curso, considerando o nível de dificuldade para obtenção da vaga, como a relação de candidatos/vaga e a quantidade de pessoas interessadas, e o nível de preparação exigida dos candidatos.

(10) Produções científicas, eventos e publicações gerais: atividades de pesquisa e estudo realizadas na instituição de ensino que resultam em livros, publicações em revistas científicas, participações em eventos (congressos, simpósios, reuniões científicas, exposições e conferências), organização de eventos internos (congressos, simpósios, reuniões científicas, exposições e conferências), organização de revistas e periódicos internos e, por fim, publicações, na mídia em geral, que fazem alusão a programas de pesquisa e centros de estudo da instituição.

(11) Título e certificação formal: documentação formal, como um certificado ou diploma, que atesta a conclusão e a aprovação do aluno no curso, concedendo-lhe, quando for o caso, o grau referente à titulação obtida. 


\begin{tabular}{|c|c|}
\hline & $\begin{array}{l}\text { (12) Ambiente do campus e da faculdade: atmosfera do campus e da instituição de } \\
\text { ensino quanto a ser um espaço dedicado ao estudo, um lugar agradável de estar, um } \\
\text { cenário que possibilite reflexão e interação entre pessoas na troca de conhecimentos. }\end{array}$ \\
\hline & $\begin{array}{l}\text { (13) Ênfase teórica e prática: postura e direcionamento da instituição de ensino quanto } \\
\text { ao embasamento teórico-conceitual em relação à abordagem prática, levando-se em conta } \\
\text { o rigor acadêmico e a vivência, exemplificação e ilustrações de situações reais. }\end{array}$ \\
\hline & $\begin{array}{l}\text { (14) Exigência: rigor e cobrança em relação à conduta do aluno e à apresentação de } \\
\text { resultados que espelhem seu aproveitamento, aprendizado, desenvolvimento, seriedade e } \\
\text { dedicação, como frequiência e presença mínima, disciplina e participação em sala de aula, } \\
\text { tempo de dedicação ao curso, avaliações de aprendizado (provas, trabalhos, papers, } \\
\text { artigos) e obediência aos prazos. }\end{array}$ \\
\hline & $\begin{array}{l}\text { (15) Preparo pessoal: nível de preparação do aluno para acompanhamento, } \\
\text { aproveitamento e contribuição ao curso, considerando sua maturidade, experiência, } \\
\text { vontade, interesse, vocação e autodisciplina. }\end{array}$ \\
\hline & $\begin{array}{l}\text { (16) Reputação: renome, tradição e imagem que a instituição de ensino desfruta } \\
\text { socialmente na visão do aluno, cujo crédito é dado, informalmente, por meio da opinião } \\
\text { de colegas, amigos, pessoas conhecidas e formadores de opinião e, formalmente, por } \\
\text { meio de avaliações e classificações realizadas por organizações independentes e } \\
\text { governamentais, como os rankings de MBAs realizados por revistas e guias de carreira, o } \\
\text { Exame Nacional de Cursos de graduação pelo MEC e a avaliação dos cursos de pós- } \\
\text { graduação stricto sensu pela CAPES. }\end{array}$ \\
\hline & $\begin{array}{l}\text { (17) Aquisição de conhecimentos: processo de aquisição e ganho de conhecimentos, } \\
\text { informacões e técnicas e/ou de agregacão de outros àqueles que o aluno domina. }\end{array}$ \\
\hline & $\begin{array}{l}\text { (18) Atualização de conhecimentos: processo de atualização e reciclagem de } \\
\text { conhecimentos, informações e técnicas aprendidos anteriormente pelo aluno. }\end{array}$ \\
\hline & $\begin{array}{l}\text { (19) Desenvolvimento de habilidades cognitivas: processo de aperfeiçoamento e } \\
\text { progresso de capacidades de conhecimento e intelectivas, considerando que o aluno } \\
\text { desenvolve raciocínio, reflexão e análise crítica, amplia a visão e o modo de pensar, traça } \\
\text { comparações sob diversos pontos de vista e exercita o "aprender a aprender". }\end{array}$ \\
\hline 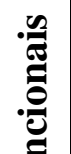 & $\begin{array}{l}\text { (20) Esforço pessoal: energia, ânimo, doação e dedicação do aluno ao curso, que envolve } \\
\text { o trabalho duro, a tentativa de fazer o melhor, de atender às expectativas e alcançar os } \\
\text { resultados esperados, abrindo mão de outros investimentos, lazer e convívio social. }\end{array}$ \\
\hline$\underbrace{\Xi}_{E}$ & $\begin{array}{l}\text { (21) Identificação e admiração: identificação do aluno com as pessoas e/ou com o } \\
\text { lugar, pelos quais demonstra admiração, tomando-os como referência para si. }\end{array}$ \\
\hline 矛 & $\begin{array}{l}\text { (22) Inspiração e motivação para o estudo: entusiasmo do aluno e estado de excitação } \\
\text { ou moção em relação ao estudo, expressando sua vontade de aprender e realizar. }\end{array}$ \\
\hline 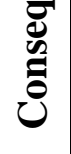 & $\begin{array}{l}\text { (23) Nível da aula: grau de qualidade da aula que possibilita o aprendizado e o } \\
\text { desenvolvimento do aluno, a partir de sua organização e preparação e da profundidade e } \\
\text { interação proporcionadas. }\end{array}$ \\
\hline & $\begin{array}{l}\text { (24) Possibilidade de compartilhar: oportunidade de o aluno interagir com outras } \\
\text { pessoas para trocar e partilhar experiências, vivências, idéias e opiniões no campo } \\
\text { profissional, assim como percepções, expectativas, descobertas, alegrias, angústias e } \\
\text { valores relativos ao momento de sua vida. }\end{array}$ \\
\hline & $\begin{array}{l}\text { (25) Rede de contatos: possibilidade de o aluno criar, expandir e manter relações com } \\
\text { pessoas de interesse. }\end{array}$ \\
\hline & o e vida pessoal: possibilidade de o aluno integra \\
\hline
\end{tabular}




\begin{tabular}{|c|c|}
\hline & $\begin{array}{l}\text { (27) Aceitação social: sensação de aprovação do aluno em seu meio social, incluindo } \\
\text { família, amigos, colegas de trabalho e chefes. } \\
\text { (28) Crescimento profissional e intelectual: reconhecimento do aluno de seu próprio } \\
\text { aprendizado ao sentir os efeitos e os resultados do aprendizado em sua atuação } \\
\text { profissional e intelectual, observando avanços em seu papel como executivo, professor, } \\
\text { pesquisador, consultor e/ou especialista, assim como o amadurecimento de suas } \\
\text { reflexões, de sua capacidade de lidar com desafios e solucionar problemas e situações } \\
\text { complexas. }\end{array}$ \\
\hline & $\begin{array}{l}\text { (29) Familiaridade e vínculo: concepção do aluno sobre a familiaridade do ambiente ao } \\
\text { sentir-se à vontade, estar em local e/ou com pessoas conhecidas e estabelecer vínculos } \\
\text { que guarda ao longo do tempo, mesmo que sejam apenas lembranças. }\end{array}$ \\
\hline & $\begin{array}{l}\text { (30) Imagem pessoal: concepção que o aluno tem de si mesmo e de como os outros o } \\
\text { vêem. }\end{array}$ \\
\hline 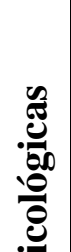 & $\begin{array}{l}\text { (31) Oportunidade de carreira e empregabilidade: concepção do aluno sobre a } \\
\text { possibilidade de ascender hierarquicamente no emprego, mudar de cargo ou de empresa, } \\
\text { iniciar novas atividades profissionais e dar origem a uma segunda carreira, assim como se } \\
\text { manter interessante para o mercado, empregável e atender às demandas e exigências de } \\
\text { recrutadores e selecionadores. }\end{array}$ \\
\hline$\frac{\sqrt{2}}{2}$ & $\begin{array}{l}\text { (32) Qualidade de vida: sensação do aluno em relação ao seu bem-estar, respeito aos } \\
\text { limites e busca do equilíbrio interno, no sentido de facilitar a existência e de tornar as } \\
\text { situações menos complexas e mais tranqüilas. }\end{array}$ \\
\hline : & $\begin{array}{l}\text { (33) Responsabilidade: sentimento do aluno de ser responsável por si mesmo e por } \\
\text { terceiros, a partir da crença de que suas decisões e conduta influenciam sua vida, família, } \\
\text { empresa, sociedade e/ou instituição de ensino. }\end{array}$ \\
\hline & $\begin{array}{l}\text { (34) Retribuição: concepção do aluno sobre a forma de compensar, devolver e dar algo } \\
\text { em troca pelo serviço, auxílio ou benefício recebido. }\end{array}$ \\
\hline & $\begin{array}{l}\text { (35) Sensação de independência: sensação do aluno criada a partir de uma situação que } \\
\text { lhe confere independência, profissional ou pessoal; envolve a possibilidade de tomar suas } \\
\text { próprias decisões, sem precisar do apoio ou do aval de terceiros e de orientar a própria } \\
\text { vida e/ou a situação segundo o que considera ideal. }\end{array}$ \\
\hline & $\begin{array}{l}\text { (36) Sensação de inteligência: sensação do aluno de sentir-se inteligente por participar } \\
\text { de um grupo que admira e/ou por alcançar os resultados esperados. }\end{array}$ \\
\hline & $\begin{array}{l}\text { (37) Sentimento de alívio: sentimento do aluno ao sair da rotina e/ou da situação que lhe } \\
\text { representa um sacrifício, como quebrar o estresse com que lida ou lidou cotidianamente e } \\
\text { fugir da situação profissional que não lhe traz ou trazia satisfação. }\end{array}$ \\
\hline & $\begin{array}{l}\text { (38) Sentimento de dever cumprido: sentimento do aluno relacionado ao fato de fazer } \\
\text { ou estar fazendo a parte que lhe cabe, de cumprir as obrigações que lhe dizem respeito. }\end{array}$ \\
\hline & $\begin{array}{l}\text { (39) Sentimento de segurança: sentimento do aluno relativo ao apoio e orientação } \\
\text { recebidos em sua passagem pela instituição de ensino. }\end{array}$ \\
\hline 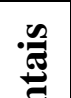 & $\begin{array}{l}\text { (40) Autoconfiança: crença do aluno de ser capaz e estar preparado para tomar decisões } \\
\text { e enfrentar os desafios que o cercam. }\end{array}$ \\
\hline 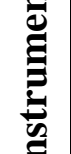 & $\begin{array}{l}\text { (41) Desenvolvimento pessoal: crença do aluno referente ao processo de tornar-se uma } \\
\text { pessoa mais preparada para a vida, por meio de seu desenvolvimento no âmbito } \\
\text { profissional e como indivíduo e cidadão. }\end{array}$ \\
\hline$\stackrel{\Xi}{\Xi}$ & $\begin{array}{l}\text { (42) Harmonia interna: crença do aluno em ter contribuído e realizado o que estava a } \\
\text { seu alcance, de estar em paz e tranqüilo com sua própria conduta. }\end{array}$ \\
\hline$\frac{0}{\frac{0}{\sigma}}$ & $\begin{array}{l}\text { (43) Pertencimento: crença do aluno de inclusão no grupo, ao sentir-se parte dele e } \\
\text { apresentar-se como um membro do mesmo. }\end{array}$ \\
\hline
\end{tabular}




\begin{tabular}{|c|c|}
\hline & $\begin{array}{l}\text { (44) Prosperidade: crença do aluno de ser e/ou tornar-se um profissional bem-sucedido, } \\
\text { com possibilidades de garantir e aumentar seu conforto e rendimentos. } \\
\text { (45) Reconhecimento social: crença do aluno sobre a percepção positiva das pessoas em } \\
\text { relação a si mesmo, atribuindo-lhe status. }\end{array}$ \\
\hline \multirow{3}{*}{ : } & (46) Apego: afeição do aluno por alguém ou algo, criando laços de amizade e proteção. \\
\hline & $\begin{array}{l}\text { (47) Auto-estima: respeito próprio e orgulho de si mesmo; auto-imagem positiva do } \\
\text { aluno. }\end{array}$ \\
\hline & (48) Auto-realização: felicidade e plenitude do aluno ao realizar o que deseja. \\
\hline
\end{tabular}

Fonte: Representação proposta pelas pesquisadoras.

\section{As inter-relações entre os elementos que compõem as cadeias meios-fim}

O estudo das inter-relações entre os 48 elementos identificados na análise de conteúdo é expresso no HVM (veja a Figura 3). A idéia dessa etapa é mapear as relações existentes entre os elementos, sejam elas relações diretas ou indiretas. As relações mais importantes foram filtradas com o estabelecimento de um ponto de corte, o que implica que, para aparecer no mapa, uma relação entre dois elementos deveria ter sido citada um número de vezes igual ou superior ao ponto de corte, caso contrário seria descartada. Utilizoutse um ponto de corte de 12, que possibilitou a representação de $72 \%$ das relações entre os elementos, fazendo jus à recomendação de Reynolds e Gutman (1988), que propõem que pelo menos dois terços delas possam ser visualizadas no mapa.

A presença de um alto ponto de corte reflete a redundância de respostas dos entrevistados, que, não raras vezes, enfatizaram os mesmos atributos, conseqüências e valores pessoais. No mapa estão indicados, entre colchetes, os números de menções feitas pelos respondentes a cada elemento (na Figura 3 o atributo corpo docente, por exemplo, foi lembrado por todos os 27 entrevistados e a autoestima, por 23 deles); entre parênteses estão os códigos da análise de conteúdo, seguidos pelo nome do elemento. A Figura 2, que antecede a apresentação do HVM (veja a Figura 3), ilustra a estruturação básica de apresentação do mapa. 
Figura 2 - Estrutura de apresentação dos elementos que compõem o mapa hierárquico de valor (HVM) (representativa)

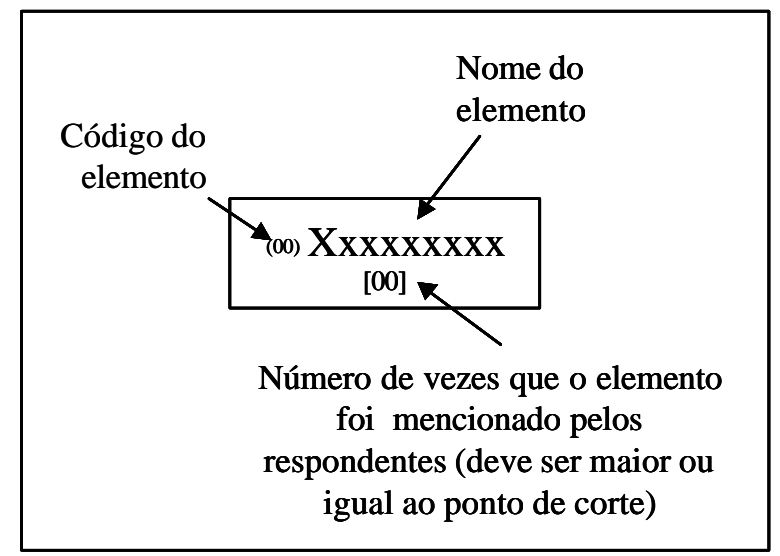

FONTE: Representação figurativa proposta pelas pesquisadoras.

Além da construção do HVM, a análise das inter-relações entre os elementos conta com a etapa de identificação das cadeias dominantes. Com base nisso, foram identificadas as interações que mais contribuem para o resultado do mapa. As orientações de percepções dominantes estão identificadas no Quadro 3, juntamente com a classificação dos elementos que compõem a interação.

As orientações dominantes, isto é, as relações mais importantes, se concentram, sobretudo, nas conseqüências psicológicas, pois das nove interações selecionadas no Quadro 3, oito incluem elementos desse nível da hierarquia de valor (crescimento profissional e intelectual, oportunidade de carreira e empregabilidade, aceitação pessoal, imagem pessoal, sentimento de dever cumprido e sentimento de segurança). Dessas interações, cinco se referem a associações entre conseqüências psicológicas e valores instrumentais, o que indica um envolvimento emocional dos alunos com esse tipo de serviço. Três elementos se destacam por comporem duas orientações dominantes: crescimento profissional e intelectual, oportunidade de carreira e empregabilidade e imagem pessoal. Tais elementos interferem mormente no valor para o aluno, conforme discorre o tópico seguinte. 
Figura 3 - Mapa hierárquico de valor (HVM) para o aluno em relação aos serviços educacionais $[\mathrm{n}=27$ ]. Ponto de corte $=12 *$

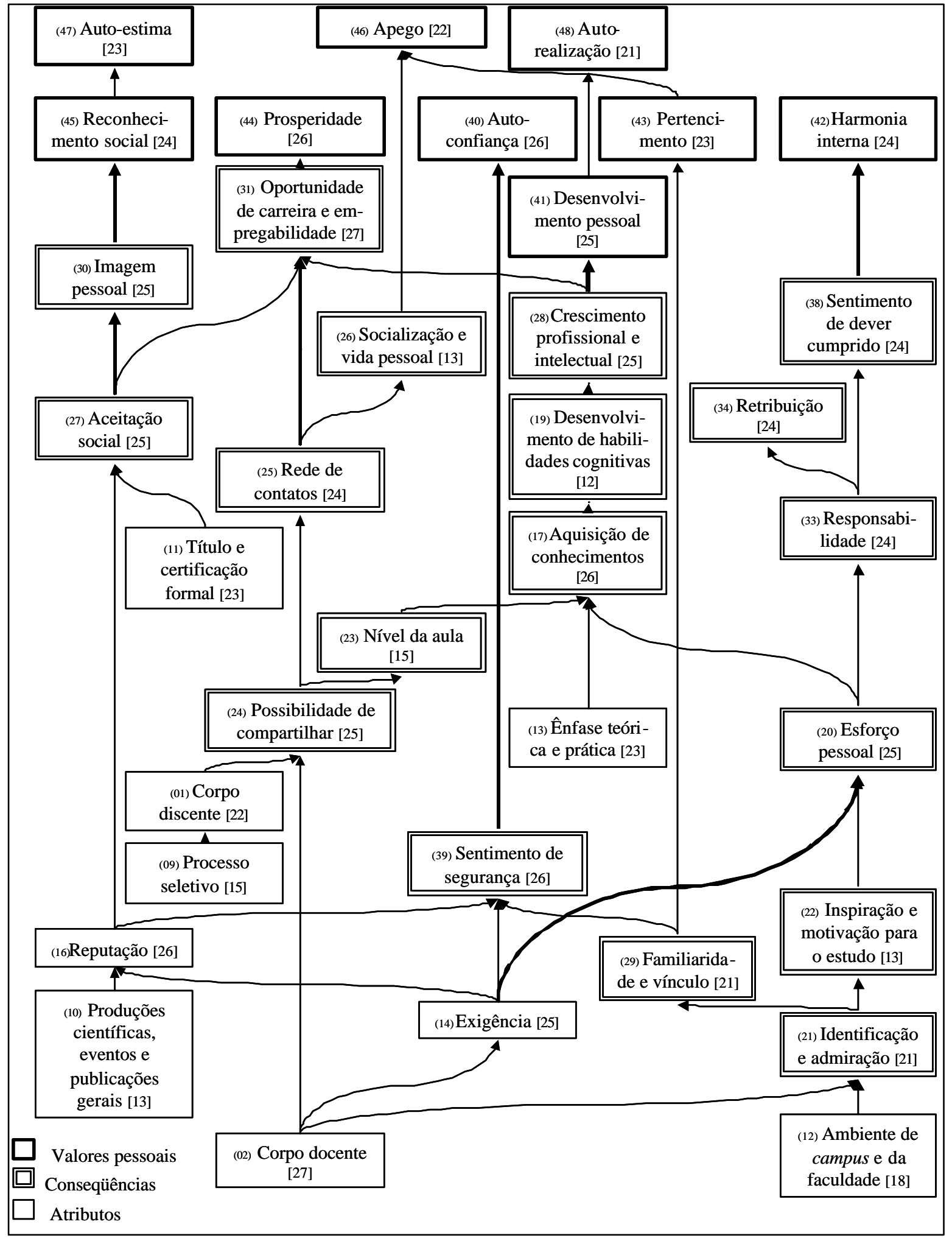

Fonte: Representação figurativa proposta pelas pesquisadoras.

* $72 \%$ das relações estão representadas no HVM, considerando os 27 respondentes. 


\section{Quadro 3 - Orientações de percepções dominantes*}

\begin{tabular}{|l|}
\hline \multicolumn{1}{|c|}{ Atributos $\rightarrow$ conseqüiências $\rightarrow$ valores pessoais } \\
\hline $\begin{array}{l}\text { Atributo abstrato } \rightarrow \text { conseqüência funcional: } \\
(14) \text { exigência } \rightarrow(20) \text { esforço pessoal. }\end{array}$ \\
\hline $\begin{array}{l}\text { Conseqüência funcional } \rightarrow \text { conseqüência psicológica: } \\
(17) \text { aquisição de conhecimentos } \rightarrow \text { (28) crescimento profissional e intelectual. }\end{array}$ \\
\hline $\begin{array}{l}\text { Conseqüência funcional } \rightarrow \text { conseqüência psicológica: } \\
(25) \text { rede de contatos } \rightarrow(31) \text { oportunidade de carreira e empregabilidade. }\end{array}$ \\
\hline Conseqüêencia psicológica $\rightarrow$ conseqüência psicológica: \\
$(27)$ aceitação social $\rightarrow(30)$ imagem pessoal. \\
\hline $\begin{array}{l}\text { Conseqüência psicológica } \rightarrow \text { valor instrumental: } \\
(28) \text { crescimento profissional e intelectual } \rightarrow(41) \text { desenvolvimento pessoal. }\end{array}$ \\
\hline $\begin{array}{l}\text { Conseqüência psicológica } \rightarrow \text { valor instrumental: } \\
(30) \text { imagem pessoal } \rightarrow(45) \text { reconhecimento social. }\end{array}$ \\
\hline $\begin{array}{l}\text { Conseqüêência psicológica } \rightarrow \text { valor instrumental: } \\
(31) \text { oportunidade de carreira e empregabilidade } \rightarrow \text { (44) prosperidade. }\end{array}$ \\
\hline $\begin{array}{l}\text { Conseqüência psicológica } \rightarrow \text { valor instrumental: } \\
(38) \text { sentimento de dever cumprido } \rightarrow \text { (42) harmonia interna. }\end{array}$ \\
\hline $\begin{array}{l}\text { Conseqüêência psicológica } \rightarrow \text { valor instrumental: } \\
\text { (39) sentimento de segurança } \rightarrow \text { (40) autoconfiança. }\end{array}$ \\
\hline
\end{tabular}

Fonte: Representação proposta pelas pesquisadoras.

* As orientações de percepções dominantes são indicadas pelo LADDERMAP no desenho do HVM.

\section{Compreender o significado do valor para o aluno em serviços educacionais}

A compreensão do valor para o aluno é possibilitada pela interpretação do HVM, que mostra as interrelações entre os elementos de acordo com os níveis (atributos, conseqüências e valores pessoais). Para favorecer o entendimento do valor para o aluno, o mapa foi desmembrado em partes, buscando-se, até por meio da combinação de algumas cadeias meios-fim, as representações-chave que configuram as expressões de valor quanto ao serviço educacional. Cada parte foi analisada separadamente, dando origem a cinco vertentes principais, a saber: (i) o significado de compartilhar; (ii) a essência do aprender; (iii) o sentido de pertencer; (iv) a expressão do status e da autoconfiança; e (v) visões sobre contribuições e deveres. O Quadro 4 mostra exemplos de cadeias meios-fim associadas a cada uma dessas representações. 
VALOR EM SERVIÇOS EDUCACIONAIS

Tânia M. Veludo-de-Oliveira - Ana Akemi Ikeda

Quadro 4 - Exemplos de cadeias meios-fim por representações de valor

\begin{tabular}{|c|c|c|c|c|c|}
\hline $\begin{array}{r}\begin{array}{r}\text { Represen- } \\
\text { tações }\end{array} \\
\text { Níveis }\end{array}$ & $\begin{array}{c}\text { O significado } \\
\text { de } \\
\text { compartilhar }\end{array}$ & $\begin{array}{l}\text { A essência do } \\
\text { aprender }\end{array}$ & $\begin{array}{l}\mathrm{O} \text { sentido de } \\
\text { pertencer }\end{array}$ & $\begin{array}{c}\text { A expressão } \\
\text { do status e da } \\
\text { autoconfiança }\end{array}$ & $\begin{array}{l}\text { Visões sobre } \\
\text { contribuições } \\
\text { e deveres }\end{array}$ \\
\hline Valores & & $\begin{array}{l}\text { Auto-realização } \\
\text { Desenvolvimento } \\
\text { pessoal }\end{array}$ & $\begin{array}{c}\text { Apego } \\
\text { Pertencimento }\end{array}$ & Autoconfiança & Harmonia interna \\
\hline Conseqüências & $\begin{array}{c}\text { Oportunidades de } \\
\text { carreira e } \\
\text { empregabilidade } \\
\text { Rede de contatos } \\
\text { Possibilidade de } \\
\text { compartilhar }\end{array}$ & $\begin{array}{l}\text { Crescimento } \\
\text { profissional e } \\
\text { intelectual } \\
\text { Desenvolvimento } \\
\text { de habilidades } \\
\text { cognitivas } \\
\text { Aquisição de } \\
\text { conhecimentos }\end{array}$ & $\begin{array}{l}\text { Familiaridade e } \\
\text { vínculo } \\
\text { Identificação e } \\
\text { admiração }\end{array}$ & $\begin{array}{l}\text { Sentimento de } \\
\text { segurança }\end{array}$ & $\begin{array}{l}\text { Sentimento de } \\
\text { dever cumprido } \\
\text { Responsabilidade } \\
\text { Esforço pessoal }\end{array}$ \\
\hline Atributos & $\begin{array}{l}\text { Corpo discente } \\
\text { Processo seletivo }\end{array}$ & $\begin{array}{c}\text { Ênfase teórica e } \\
\text { prática }\end{array}$ & Corpo docente & $\begin{array}{l}\text { Produções } \\
\text { científicas, } \\
\text { eventos e } \\
\text { publicações } \\
\text { gerais }\end{array}$ & $\begin{array}{c}\text { Exigência } \\
\text { Corpo docente }\end{array}$ \\
\hline
\end{tabular}

Fonte: Representação figurativa proposta pelas pesquisadoras.

O significado de compartilhar se relaciona ao modo como aluno participa dos grupos envolvidos com a escola, assim como o de professores, coordenadores, colegas de turma e ex-alunos, partilhando experiências, oportunidades de carreira e amizade. A essência do aprender corresponde ao valor envolvido no processo de aprendizagem, que modifica a postura do educando tanto profissional como pessoalmente, à medida que possibilita o domínio de instrumentos de trabalho e propicia amadurecimento das reflexões e das capacidades de lidar com desafios. O sentido de pertencer é a representação ligada à necessidade de sentir-se integrado, aceito e incluído em um grupo. O pertencimento pode estar relacionado ao mercado de trabalho, considerando que o título de um curso proporciona a aceitação social do aprendiz em seu meio profissional. Além disso, também pode estar ligado à identificação e admiração pelos professores ou pela instituição educacional, desenvolvendo um sentimento de apego e de pertencimento ao ambiente escolar. A expressão do status e da autoconfiança se refere à auto-afirmação e à auto-aprovação que interferem no modo do estudante se ver perante os demais, influenciando a imagem que tem de si mesmo e a forma de se valorizar. As visões sobre contribuições e deveres dizem respeito à maneira de o aluno compensar e devolver algo em troca pelo 
serviço, apoio e benefícios recebidos, retribuindo a escola, a família e, eventualmente, a empresa que facilitou sua participação no curso.

$\mathrm{Na}$ pesquisa, foram verificadas diferenças na maneira de o aluno de MBA compreender o significado de compartilhar e a essência de aprender, em comparação aos mestrandos e doutorandos, além de particularidades em suas visões sobre contribuições e deveres. No MBA, sobressaem as relações com os pares, o enfoque imediatista do aprendizado e a visão do curso como um direito adquirido. Os estudantes do stricto sensu, por sua vez, priorizam o contato com os docentes, buscam a auto-realização e procuram atender às solicitações da escola como forma de compensar o benefício recebido.

\section{CONSIDERAÇÕES FINAIS}

O estudo do valor por meio das cadeias meios-fim fornece um caminho relativamente simples para a caracterização das inter-relações cognitivas entre atributos, conseqüências e valores pessoais, nas quais as características dos produtos ganham significado devido à associação com as consequiências advindas de seu uso e, por conseguinte, com o alcance de valores pessoais. Em educação, o estudo do valor se mostra uma abordagem interessante por priorizar o longo prazo, já que os valores pessoais nem sempre são alcançados no momento da prestação do serviço, assim como os efeitos da educação, que se manifestam no decorrer do tempo.

No Quadro 5 são condensadas as principais sugestões de como a escola pode oferecer valor em seus serviços, de acordo com cada uma das representações-chave.

Quadro 5 - A oferta de serviços educacionais de valor para o aluno

\begin{tabular}{|c|l|}
\hline Representações & \multicolumn{1}{|c|}{ Como oferecer valor? } \\
\hline $\begin{array}{c}\text { O significado de } \\
\text { compartilhar }\end{array}$ & $\begin{array}{l}\text { Proporcionar trocas entre o aluno e diferentes públicos, priorizando o } \\
\text { contato do estudante com os professores da instituição e com os colegas de } \\
\text { curso e, por outro lado, proporcionando contatos com ex-alunos, alunos de } \\
\text { cursos de áreas afins, professores e alunos de outras instituições, nacionais } \\
\text { e internacionais, membros da comunidade acadêmica e empresarial, dentro } \\
\text { e fora da sala de aula. }\end{array}$ \\
\hline $\begin{array}{c}\text { A essência do } \\
\text { aprender }\end{array}$ & $\begin{array}{l}\text { Garantir as condições de aprendizado ao aluno e o comprometimento do } \\
\text { professor com a instituição e com o desenvolvimento do educando; prezar } \\
\text { por um nível de exigência que impulsione o crescimento do aprendiz e por } \\
\text { procedimentos que o levem a reconhecer o próprio progresso, } \\
\text { apresentando justificativas consistentes que expliquem as decisões da }\end{array}$ \\
\hline
\end{tabular}


Tânia M. Veludo-de-Oliveira - Ana Akemi Ikeda

\begin{tabular}{|c|l|}
\hline & escola que interferem em seu aprendizado. \\
\hline & $\begin{array}{l}\text { Fomentar a idéia de obtenção do título ou da certificação associada ao } \\
\text { diferencial de imagem proporcionado pela instituição, devido à seriedade, } \\
\text { exigência e qualidade comprovadamente reconhecidas. Promover o } \\
\text { envolvimento do aluno com a escola, possibilitando sua participação em } \\
\text { atividades extracurriculares e a permanência física do estudante no } \\
\text { pertencer } \\
\text { estabelecimento de ensino, com o intuito de demonstrar que a escola se } \\
\text { importa com ele e abre espaço para acolhê-lo durante e após o curso. }\end{array}$ \\
\hline $\begin{array}{c}\text { A expressão do } \\
\text { status e da }\end{array}$ & $\begin{array}{l}\text { Evidenciar os motivos que justificam a boa reputação da instituição de } \\
\text { ensino, embasando os argumentos com comprovações sobre a aceitação e } \\
\text { autoconfiança }\end{array}$ \\
\hline $\begin{array}{c}\text { Visóes sobre } \\
\text { contribuições e e }\end{array}$ & $\begin{array}{l}\text { Reconhecer perante o educando o seu esforço em cumprir e administrar os } \\
\text { compromissos para realização do curso, incentivando-o a prosseguir com a } \\
\text { dedicação para atingir seus objetivos de aprendizado. Possibilitar o } \\
\text { vínculo do aluno com a instituição após o curso, orientando-o a respeito de } \\
\text { possíveis formas de auxílio e contribuições com a escola. }\end{array}$ \\
\hline
\end{tabular}

Fonte: Representação proposta pelas pesquisadoras.

Além de sugestões genéricas, é possível particularizá-las aos cursos analisados. Em relação ao curso MBA, em específico, destacam-se as seguintes recomendações:

- conscientizar os alunos dos sacrifícios envolvidos no processo de volta às aulas, procurando incentivá-los a superar as dificuldades e a serem proativos na busca de seu aprendizado;

- conscientizar os alunos do ganho cognitivo que o curso proporciona, independentemente da aplicação imediata do conhecimento adquirido;

- $\quad$ antes do início de cada módulo do curso, explicar aos alunos o seu objetivo, apresentar as aulas e palestras que compõem o módulo e justificar o porquê de sua importância no aprendizado do estudante, vinculando as argumentações aos critérios de empregabilidade do mercado;

- $\quad$ propor o desenvolvimento de um trabalho ao final de cada módulo, no qual o aluno indique uma situação em que tenha implantado (ou que pretenda implantar) o conhecimento adquirido;

- $\quad$ estabelecer uma rotina para ouvir as demandas dos alunos, a partir de reuniões com a coordenação ou da eleição de um representante de classe;

- lembrar os professores de que os alunos têm expectativas de participação na aula, para que, quando seja possível e apropriado, eles possam expor suas opiniões e situações vivenciadas que guardem relação com o tema, formalmente, por meio de trabalhos em grupo e, informalmente, por meio de intervenções durante as sessões de aula. Uma sugestão para 
promover a interação da turma com o docente é polemizar algum ponto do assunto para suscitar debates.

Para os cursos de mestrado e doutorado são feitas as seguintes sugestões:

- disponibilizar, na bibliografia da disciplina, a referência de artigos, publicações e materiais que espelhem o estado da arte no tema, incluindo textos clássicos e produções recentes;

- incentivar o acompanhamento próximo do professor-orientador em relação às atividades desenvolvidas pelo aluno. O professor-orientador e o aluno poderiam preparar uma programação de atividades a serem cumpridas ao longo do curso, respeitando prazos e escolhendo as disciplinas conforme o interesse para desenvolvimento da dissertação ou tese;

- incentivar a interdisciplinaridade, com a oferta de cursos que envolvam mais de uma área de concentração;

- garantir um número suficiente de disciplinas restritas aos alunos de doutorado;

- $\quad$ proporcionar disciplinas focadas na formação de professores, pesquisadores e consultores, o que poderia ser enfatizado, respectivamente, por meio da oferta de: (i) disciplinas de didática, em diferentes níveis de aprofundamento; (ii) uma disciplina com foco no desenvolvimento de procedimentos metodológicos para aplicação em problemas de pesquisa; e, por fim, (iii) uma disciplina voltada à resolução de casos, segundo enfoque multidisciplinar;

- $\quad$ promover o contato com a graduação, explicando aos alunos de graduação o intuito da participação do pós-graduando em seu curso, por meio da devida estruturação do programa de monitoria.

O valor não é criado somente em curto prazo. Os profissionais da educação não podem, em absoluto, render-se cegamente à idéia da satisfação momentânea do estudante, pois isso pode significar estar indo contra seus próprios interesses no futuro. É válido lembrar que, passado o momento do sacrifício, o educando tende a reconhecer positivamente a exigência a que foi submetido na escola, por associá-la às recompensas posteriores advindas do esforço despendido, que proporcionaram aquisição de conhecimentos, desenvolvimento de habilidades cognitivas, crescimento pessoal e reconhecimento social, entre outros. Quando um estudante se inscreve em um curso, não está simplesmente buscando as aulas, o acesso à biblioteca ou o diploma; está buscando instrução, desenvolvimento pessoal, reputação, possibilidades de ascensão social e de carreira. Analogamente, o anseio do aluno por freqüentar um curso com infra-estrutura de ponta perde força caso os recursos técnicos, computacionais e audiovisuais disponíveis não proporcionem e estimulem seu aprendizado, pois as características dos 
produtos somente têm utilidade ou sentido quando servem a alguma necessidade fundamental ou a valores pessoais. Identificar conexões entre as características do produto, de um lado, e os valores pessoais, de outro, é importante para prover programas e produtos com capacidade de criar valor aos públicos da organização, o que é válido também para as instituições educacionais.

Sobre as limitações do presente estudo, vale lembrar que apenas uma instituição foi pesquisada, o que não permite maiores generalizações. Seria interessante averiguar outras instituições e comparálas. Técnicas de análise mais estruturadas também ficam como sugestões, uma vez que esta pesquisa proporciona bases para continuidade e aprofundamento do tema. Outras recomendações para pesquisas futuras:

- $\quad$ analisar a visão dos alunos a respeito de quem são os públicos-alvo do serviço educacional;

- compreender e comparar o valor em serviços educacionais para alunos de diferentes níveis de ensino e de outros cursos;

- compreender o valor em serviços educacionais para públicos que estão indiretamente relacionados com o ensino, como grupos da sociedade, família e organizações que contratam o estudante;

- $\quad$ compreender o valor em serviços educacionais para os professores;

- $\quad$ analisar o que os recrutadores e selecionadores esperam da formação educacional de um profissional;

- $\quad$ analisar instrumentos e critérios de avaliação de cursos, buscando a inclusão de aspectos de valor e visão em longo prazo e não apenas a mensuração da satisfação momentânea do aluno.

\section{REFERÊNCIAS BIBLIOGRÁFICAS}

BOTSCHEN, G.; THELEN, E. M.; PIETERS, R. Using means-end structures for benefit segmentation an application to services. European Journal of Marketing, v. 33, n. 1-2, p. 38-58, 1999.

DIBLEY, A.; BAKER, S. Uncovering the links between brand choice and personal values among young British and Spanish girls. Journal of Consumer Behaviour, v. 1, n. 1, p. 77-93, 2001. 
FOOTE, D.; LAMB, K. Eliciting information about the values of HRM practitioners using laddering interviews. Business Ethics: A European Review, v. 11, n. 3, p. 244-252, 2002.

GENGLER, C. E.; MULVEY, M. S.; OGLETHORPE, J. E. A means-end analysis of mother's infant feeding choices. Journal of Public Policy \& Marketing, v. 18, n. 2, p. 172-88, 1999.

GENGLER, C. LADDERMAP User's Manual. New Jersey: Camden, 1995.

GENGLER, C.; REYNOLDS, T. Consumer understanding and advertising strategy: analysis and strategic translation of laddering data. Journal of Advertising Research, v. 35, n. 4, p. 19-32, 1995.

GRUNERT, K. G.; GRUNERT, S. C. Measuring subjective meaning structures by the laddering method: theoretical considerations and methodological problems. International Journal of Research in Marketing, v. 12, n. 3, p. 209-25, 1995.

GUTMAN, J. A means-end chain model based on consumer categorization processes. Journal of Marketing, v. 46, p. 60-72, 1982.

GUTMAN, J.; MIAOULIS, G. Communicating a quality position in service delivery: an application in higher education. Managing Service Quality, v. 13, n. 2, p. 105-11, 2003.

HOLBROOK, M. B. Emotion in the consumption experience: towards a new model of the human consumer. In: PETERSON, R. et al. (Eds.). The Role of Affect in Consumer Behavior: Emerging Theories and Applications. Lexington: Lexington Books, p. 17-52, 1986.

HOLBROOK, M. B. The nature of customer value: an axiology of services in the consumption experience. In: OLIVER, R. L.; RUST, R. T. (Eds.). Services Quality: New Directions in Theory and Practice. Thousand Oaks: Sage, p. 21-71, 1994.

HOWARD, J. C. Consumer Behavior: Application of Theory. New York: McGraw Hill, 1977. 
LASTOVICKA, J. L. LADDERMAP: version 4.0 by Chuck Gengler. Journal of Marketing Research, v. 32, n. 4, p. 494-7, 1995.

LEÃO, A. L. M. de S.; MELLO, S. C. B. Mensurando customer value através do método laddering: uma proposta de aplicação da técnica para o ambiente virtual. In: ENCONTRO NACIONAL DA ASSOCIAÇÃO NACIONAL DOS PROGRAMAS DE PÓS-GRADUAÇÃO EM ADMINISTRAÇÃO, 25., 2001, Campinas. Anais. Campinas: ANPAD, 2001.

LeBLANC, G.; NGUYEN, N. Listening to the customer's voice: examining perceived service value among business college students. International Journal of Education Management, v. 13, n. 4, p. 18798, 1999.

LEHMANN, D. R. Journal evolution and the development of marketing. Journal of Public Policy \& Marketing, v. 24, n. 1, p. 137-42, 2005.

LIN, C. Attribute-consequence-value linkages: a new technique for understanding customer's product knowledge. Journal of Targeting, Measurement and Analysis for Marketing, v. 10, n. 4, p. 339-52, 2002.

LIN, C.; FU, H. Exploring logic construction on MECs to enhance marketing strategy. Marketing Intelligence \& Planning, v. 19, n. 5, p. 362-7, 2001.

MANYIWA, S.; CRAWFORD, I. Determining linkages between consumer choice in a social context and the consumer's value: a means-end approach. Journal of Consumer Behaviour, v. 2, n. 1, p. 54-70, 2002.

MAKATOUNI, A. What motivates consumers to buy organic food in the UK? Results from a qualitative study. British Food Journal, v. 104, n. 3/4/5, p. 345-52, 2002.

OLSON, J.; REYNOLDS, T. Understanding consumer's cognitive structures: implications for advertising strategy. In: PERCY, L.; WOODSIDE, A. (Eds.). Advertising and Consumer Psychology. Lexington: Lexington Books, p. 77-90, 1983. 
RAE-revista de administração de empresas. São Paulo: FGV-EAESP,v. 43, n. 2, abr./jun. 2003. Fórum Educação em Administração.

REYNOLDS, T. J.; GUTMAN, J. Laddering theory, method, analysis, and interpretation. Journal of Advertising Research, v. 28, p. 11-31, 1988.

REYNOLDS, T.; WHITLARK, D. Applying laddering data to communications strategy and advertising practice. Journal of Advertising Research, v. 35, n. 4, p. 9-16, 1995.

ROKEACH, M. The Nature of Human Values. New York: Free Press, 1973.

RUGG, G.; EVA, M.; MAHMOOD, A.; REHMAN, N.; ANDREWS, S.; DAVIES, S. Eliciting information about organizational culture via laddering. Information Systems Journal, v. 12, p. 215-29, 2002.

SHETH, J. N.; NEWMAN, B. I.; GROSS, B. L. Why we buy what we buy: a theory of consumption values. Journal of Business Research, v. 22, p. 159-70, 1991.

URALA, N.; LÄHTEENMÄKI, L. Reasons behind consumer's functional food choices. Nutrition \& Food Science, v. 33, n. 4, p. 148-158, 2003.

VALETTE-FLORENCE, P.; RAPACCHI, B. Improvements in means-end chain analysis: using graph theory and correspondence analysis. Journal of Advertising Research, p. 30-45, 1991.

VELUDO-DE-OLIVEIRA, T.; IKEDA, A. O conceito de valor para o cliente: definições e implicações gerenciais em marketing. Gestão.Org, Recife, v. 3, n. 1, jan./abr. 2005. Disponível em: <www.gestaoorg.dca.ufpe.br>, acessado em: 13 mar. 2006.

VINSON, D. E.; SCOTT, J. E.; LAMONT, L. M. The role of personal values in marketing and consumer behavior. Journal of Marketing, v. 2, p. 44-50, 1977. 
VRIENS, M.; HOFSTEDE, F. T. Linking attributes, benefits and consumer values. Journal of Marketing Research, v. 12, n. 3, p. 4-10, 2000.

WANSINK, B. New techniques to generate key marketing insights. Journal of Marketing Research, v. 12, n. 2, p. 28-36, 2000.

WOODRUFF, R. B. Customer value: the next source of competitive advantage. Journal of Academy of Marketing Science, v. 25, n. 2, p. 139-54, 1997.

WOODRUFF, R. B.; GARDIAL, S. F. Know your customer: new approaches to understanding customer value and satisfaction. Malden: Blackwell, 1996.

YOUNG, S; FEIGIN, B. Using the benefit chain for improved strategy formulation. Journal of Marketing, v. 39, p. 72-74, 1975.

ZEITHAML, V. Consumer perceptions of price, quality and value: a means-ends model and synthesis of evidence. Journal of Marketing, v. 52, p. 2-22, 1988. 


\section{Artigo recebido em 27.05.2004. Aprovado em 10.03.2006.}

\section{Tânia Modesto Veludo-de-Oliveira}

Doutoranda da Cardiff Business School (UK) e bolsista da CAPES.

Interesses de pesquisa nas áreas de comportamento do consumidor, marketing social e marketing educacional.

Email: tveludo@usp.br

Endereço: Rua Dr. Vasco de Andrade, 94 apto. 201, Boa Vista, Uberaba - MG, 38017-200.

\section{Ana Akemi Ikeda}

Professora Associada da área de Marketing da FEA-USP. Doutora em Administração pela FEA-USP. Interesses de pesquisa nas áreas de comportamento do consumidor, marketing educacional e marketing de serviços.

Email: anaikeda@usp.br

Endereço: Av. Prof. Luciano Gualberto, 908 sala e-104, São Paulo - SP, 05508-900. 